\title{
The portfolio effect cushions mosquito populations and malaria transmission against vector control interventions
}

\author{
Gerry F. Killeen ${ }^{1,2^{*}}$ and Thomas E. Reed ${ }^{3}$
}

\begin{abstract}
Background: Portfolio effects were first described as a basis for mitigating against financial risk by diversifying investments. Distributing investment across several different assets can stabilize returns and reduce risks by statistical averaging of individual asset dynamics that often correlate weakly or negatively with each other. The same simple probability theory is equally applicable to complex ecosystems, in which biological and environmental diversity stabilizes ecosystems against natural and human-mediated perturbations. Given the fundamental limitations to how well the full complexity of ecosystem dynamics can be understood or anticipated, the portfolio effect concept provides a simple framework for more critical data interpretation and pro-active conservation management. Applied to conservation ecology purposes, the portfolio effect concept informs management strategies emphasizing identification and maintenance of key ecological processes that generate complexity, diversity and resilience against inevitable, often unpredictable perturbations.

Implications: Applied to the reciprocal goal of eliminating the least valued elements of global biodiversity, specifically lethal malaria parasites and their vector mosquitoes, simply understanding the portfolio effect concept informs more cautious interpretation of surveillance data and simulation model predictions. Malaria transmission mediated by guilds of multiple vectors in complex landscapes, with highly variable climatic and meteorological conditions, as well as changing patterns of land use and other human behaviours, will systematically tend to be more resilient to attack with vector control than it appears based on even the highest quality surveillance data or predictive models.
\end{abstract}

Conclusion: Malaria vector control programmes may need to be more ambitious, interpret their short-to-medium term assessments of intervention impact more cautiously, and manage stakeholder expectations more conservatively than has often been the case thus far.

Keywords: Malaria, Plasmodium, Anopheles, Mosquito, Vector control, Elimination, Ecology

\section{Background}

Conservation biologists have recently adopted the portfolio effect concept from economics [1], to guide their thinking in relation to ecosystem conservation [2]. The implications of such simple probability theory for financial investments are rather obvious and now widely accepted: diversification stabilizes investment portfolios, thereby reducing risks of catastrophic losses [1].

\footnotetext{
*Correspondence: gkilleen@ihi.or.tz

${ }^{1}$ Environmental Health and Ecological Sciences Department, Ifakara

Health Institute, Ifakara, United Republic of Tanzania

Full list of author information is available at the end of the article
}

Distributing investment across several different assets can stabilize returns and reduce risks by statistical averaging of individual asset dynamics that often correlate weakly or negatively with each other [1].

The same simple probability theory [1] is equally applicable to complex ecosystems, which are buffered against natural and human-mediated perturbations by biological and environmental diversity [2]. Rather than rely on prescriptive model predictions, the uncertainties of which are determined by fundamental limitations to how well the full complexity of ecosystem dynamics can be understood or anticipated, the portfolio effect concept provides 
a simple framework for more critical data interpretation and pro-active conservation management [2]. Merely understanding the portfolio effect concept informs management strategies emphasizing identification and maintenance of key ecological processes that generate complexity, diversity and resilience against inevitable and often unpredictable perturbations [2].

\section{Implications for malaria vector control and surveillance}

The implications of the portfolio effect concept should also be considered when interpreting malaria vector surveillance data and the predictions of simulation models fitted to them. When considering how uncertain models might be, it is important to distinguish between the likely causes of unbiased imprecision and systematic inaccuracy. The portfolio effect introduces the latter: by design, mathematical models are deliberately less complex than the biological system they are intended to mimic [3-5], and no dataset can capture all the different circumstances a real biological system experiences. There is, therefore, an inevitable tendency for mathematical models to underestimate the complexity and associated resilience of natural biological systems. Expressed in simple interpretational terms, mosquito populations and malaria transmission will tend be more resilient against control efforts than face-value interpretation of data or predictive mathematical models suggest.

The ubiquitous and extreme heterogeneities of vector density and vectorial capacity that occur across remarkably fine geographic scales have long been recognized as crucial factors underpinning the notorious intransigence of malaria transmission to intervention efforts [6-8]. However, beyond heterogeneities of vector density resulting in local foci where transmission is far more intense and stable than the landscape-wide average, vector biodiversity and heterogeneities in the environments they live in create portfolio effects that diversify the properties of malaria transmission.

Modelling analyses that incorporated heterogeneities of mosquito behaviour were centrally important to the illustrations of how residual malaria transmission [9-12] persists so robustly in Africa after scale-up of indoor residual spraying (IRS) $[13,14]$. Since then, a variety of models have been used to illustrate this same point [1530]. However, no existing model captures the full range of all relevant mosquito behaviour in real transmission systems with biodiversity spanning dozens of vectors [31], several of which may occur in any given setting. While such models can be improved, progress towards more realistic representations of complex real-life vector systems will be limited by data and understanding for the foreseeable future $[5,32]$. In the meantime, it may be prudent to bear in mind the following rule of thumb: the more diverse and variable the life histories of malaria vectors are, the less likely it is that any given vector control approach with eliminate all the malaria transmission they mediate.

For example, the more mosquito species a malaria parasite can use as a vector, the higher the probability that one or more of those species will become resistant to any given insecticide compared to a situation where only a single vector species is involved. Given that there is a stochastic element to resistance evolution, the more vector species are present, the more likely that at least one of them will become physiologically resistant to insecticides and continue to mediate transmission despite high coverage of long-lasting insecticidal nets (LLINs) and/or IRS. For example, while Anopheles gambiae has been greatly reduced in numbers across many parts of Africa following scale-up of pyrethroid-based LLINs [33, 34], highly pyrethroid-resistant Anopheles funestus [35] may persist and mediate intense transmission [36].

Also, differences in the behaviour of mosquito species have long been known to render malaria transmission frustratingly resilient against attack with IRS $[14,37$, 38]. Behaviourally selective vector control interventions, such as LLINs and IRS, have successfully eliminated entire populations of some of the world's most important malaria vectors, such as An. gambiae and An. funestus in Africa, Anopheles punctulatus and Anopheles koliensis in Oceania, or Anopheles darlingi in South America. However, elimination of malaria transmission remains elusive in most settings because mosquito species persist which are less efficient vectors but also exhibit outdoor resting and feeding behaviours that are far less vulnerable to these indoor-targeted approaches $[9,10,28,34,39]$.

Furthermore, fine-scale environmental variations in the relative abundance and availabilities of essential blood host and resting site resources can drive huge variations in the behavioural choices that mosquitoes exhibit in different parts of a given landscape. Taking Anopheles arabiensis as an African example of an important vector of residual malaria transmission that exhibits notoriously plastic feeding behaviours, the proportion of indoorfeeding mosquitoes that rest indoors until the following morning can vary by two orders of magnitude [40]. More tellingly, An. arabiensis can exhibit both extremes of feeding predominantly on either people or cattle, even in different family compounds within the same small village [41, 42].

Consequently, there is no single correct choice amongst insecticidal vector population suppression interventions that target this species when they either attack humans while asleep indoors (LLINs/IRS), when they attack people outdoors (vapour-phase insecticides 
or insecticide-treated clothes), or when they attack cattle (veterinary formulations of systemic insecticides, often referred to as endectocides) [29] (Fig. 1). Because of such fine-scale heterogeneities in the behavioural choices such phenotypically plastic species make in response to variations they encounters in their environments [43, 44], quite large local gaps in biological coverage [20] inevitably arise regardless of which of these approaches is chosen [29]. Given that such extreme heterogeneities of behaviour an occur within even a single species over distances of metres rather than kilometres [43, 44], it will never be possible for control programmes to map them out across national scales with sufficient resolution to enable accurate, biologically relevant targeting of each individual intervention [29].

The diversity of behaviours expressed by a single vector species through phenotypic plasticity is further exacerbated by the fact that they usually co-exist alongside other vectors with different behavioural preferences (Fig. 1). Such guilds of multiple vectors may span a remarkably wide range of behavioural phenotypes, and the African scenario presented in Fig. 1 is far less biodiverse than many settings in southeast Asia [9, 45-47]. It will therefore be necessary to design packages of complementary vector control interventions based on the range of behaviours observed in nationally representative surveys, rather than their mean values, so that these

LOCALIY-VARIABLE VALUES FOR A GUILD OF FOUR COMMON AFRICAN VECTORS:

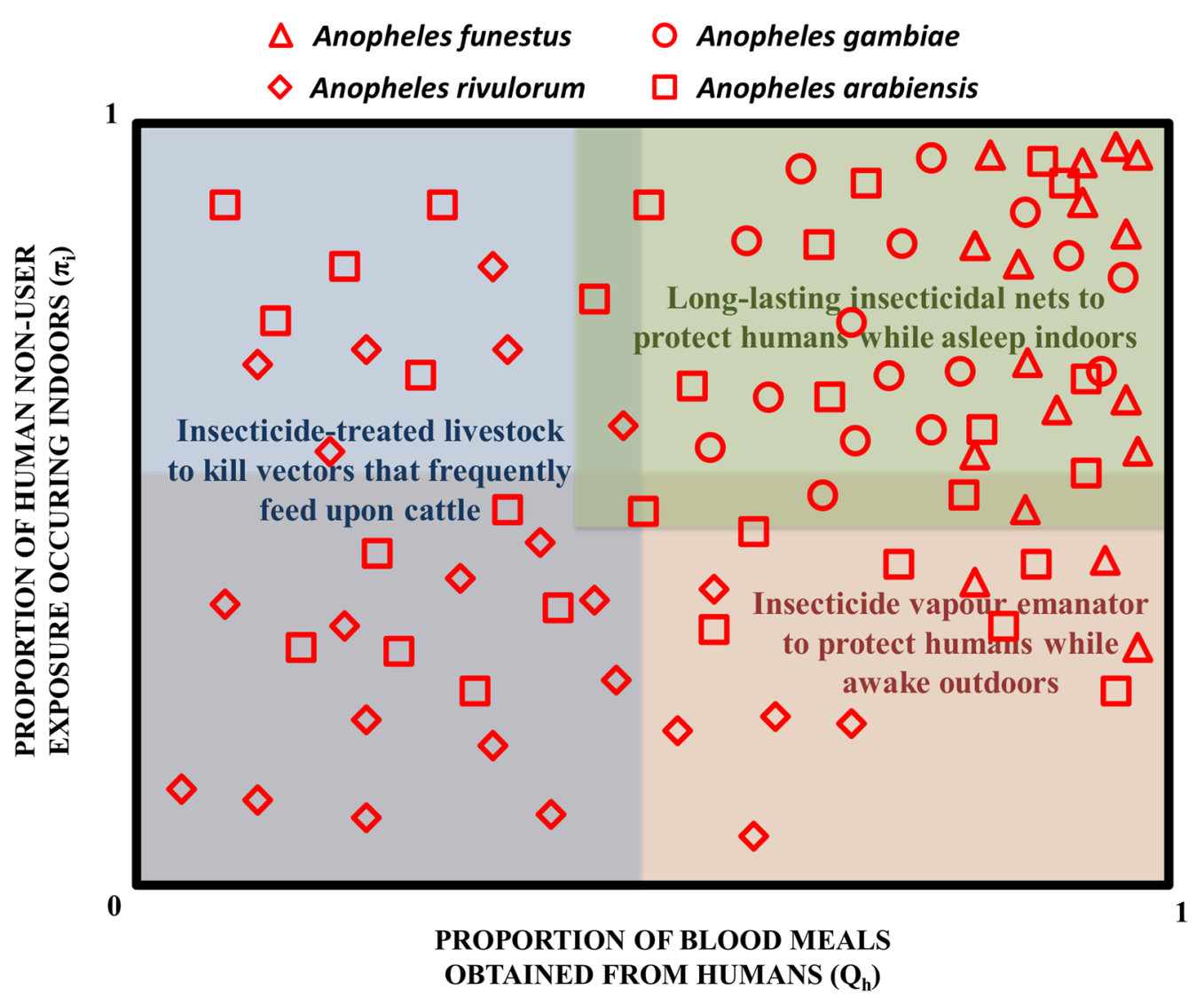

Fig. 1 A schematic illustration of how a hypothetical but typical guild of four common African malaria vectors may span the full range of behavioural preferences for biting humans indoors versus outdoors, and biting humans versus animals. While An. funestus has a very strong preference for humans [28, 42], it is capable of biting early in the evening or late in the morning when humans are active and exposed outside the protective reach of long-lasting insecticidal nets [66-70]. Anopheles gambiae has a slightly less strict preference for feeding upon humans [28, 42] and can also feed outdoors at dawn and dusk to some degree in some locations [17, 71]. Anopheles arabiensis is notoriously phenotypically plastic in its expression of both behaviours, spanning a very wide range of human blood indices $[28,42]$ and often biting outdoors in the early evenings in settings where effective indoor vector control has been implemented [17,72]. While Anopheles rivulorum typically prefers to feed upon animals, and tends to be most active at dusk and dawn, it is nevertheless a vector of malaria in its own right, contributing significantly to residual transmission in some settings $[51,73,74]$ 
intervention combinations are broadly applicable and robust to local variations in the behaviours targeted by each component control measure [29]. Such a multiintervention approach would also help address the urgent need to implement insecticide resistance management strategies [48], by exploiting multiple interventions that allow different, complementary insecticide classes to be deployed as combinations delivered through distinct products.

Complex interactions between landscape hydrology, weather patterns and vector biology also generate diversity in the characteristics and distribution of aquatic habitats that one or more vector species utilize, as well as diversity in the seasonality in their population dynamics. As a result, the probability that at least one habitat type will occur that is difficult to target with larval control is increased relative to stereotyped expectations based on any single species. For example, much has been written about the opportunities and obstacles to targeting members of the An. gambiae complex based on the stereotyped assumption that they predominantly breed in clean, sunlit, rain-fed "pools and puddles" [49], when the reality is that these species exhibit considerable plasticity in their oviposition behaviour and often do so in impressive style [50, 51]. Anopheles gambiae sensu lato larvae have been repeatedly documented in atypical, non-preferred, often cryptic habitats such as tree holes, borrow pits, the vegetated fringes of fast-flowing rivers, and water storage containers, especially during the dry season when options are otherwise limited [50,51]. Critically, the larval ecology of this complex is notoriously variable between and within species of the complex
[52-54], so the exact survival strategy exhibited in any given location is idiosyncratic and essentially impossible for even experts to reliably predict $[55,56]$. Variations in larval ecology between two or more vectors, or between the seasonal dynamics of different habitats in the same ecosystem, also create diversity of seasonality that provides refuges against vector control interventions. For example, a small sub-set of locations with high water tables that support permanent lakes, ponds and swamps, or perennial rivers and streams create local conditions where transmission occurs all year round. In Africa south of the Sahara, such hydrological conditions create a niche for An. funestus [51], perhaps the most efficient vector of malaria in the world and now highly resistant to pyrethroids all across its distribution [35]. In some locations, transmission peaks well into the dry season when receding water bodies create abundant habitat. Perhaps the most dramatic historical example is the dry season malaria epidemics in Sri Lanka caused by Anopheles culicifacies breeding in dried-out river beds [57]. Where two or more vector species exhibit seasonal peaks of transmission at different times of the year, or even where multiple habitat types for a single vector species exhibit different seasonal patterns, transmission seasonality is diversified and therefore becomes more resilient to any transmission control measure applied discontinuously. Even within the An. gambiae complex, Anopheles coluzzii can aestivates through the Sahelian dry season before reawakening a month or two in advance of the first rains, approximately 6 months apart from its far more raindependent siblings, An. arabiensis and An. gambiae (Fig. 2) [58]. There is therefore no perfect time of year to

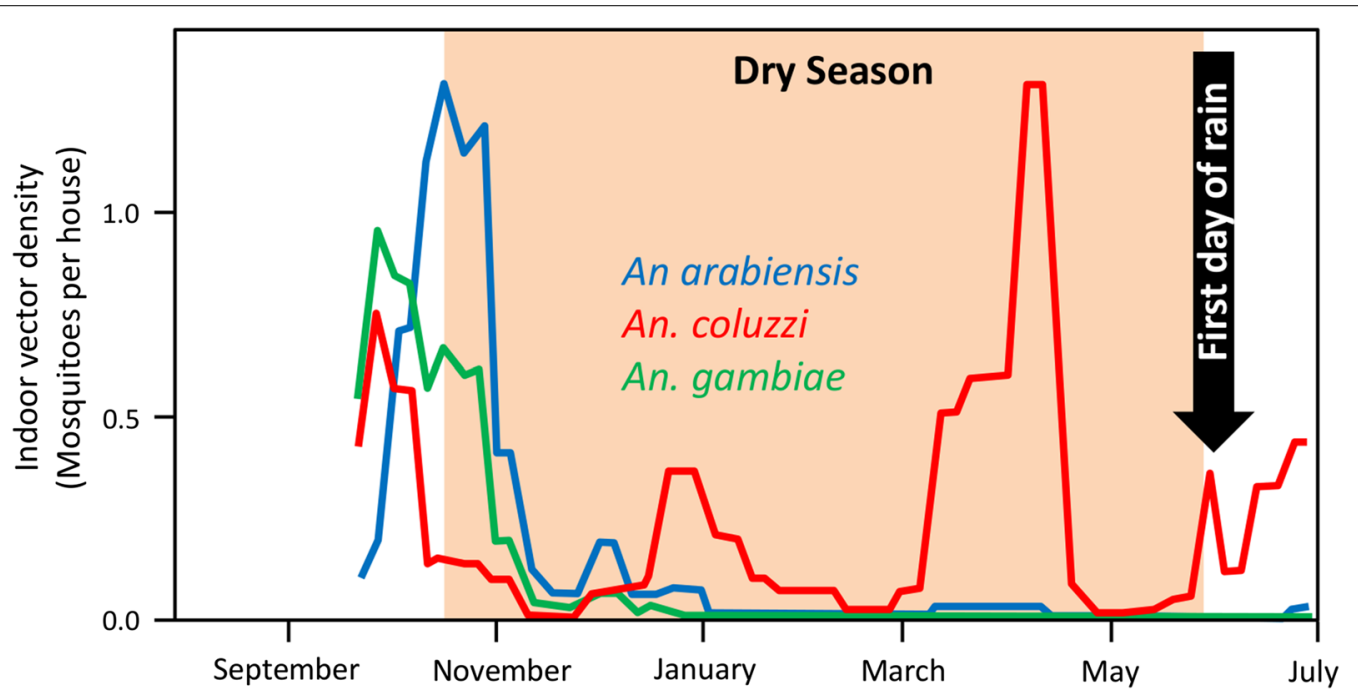

Fig. 2 An example of how the seasonality of three sympatric sibling vector species from a single complex can exhibit very different seasonality patterns in the same location. In this case An. arabiensis, An. coluzzi and An. gambiae in the Sahel of Mali, redrawn from Ref. [58] for the 2007 to 2008 season 


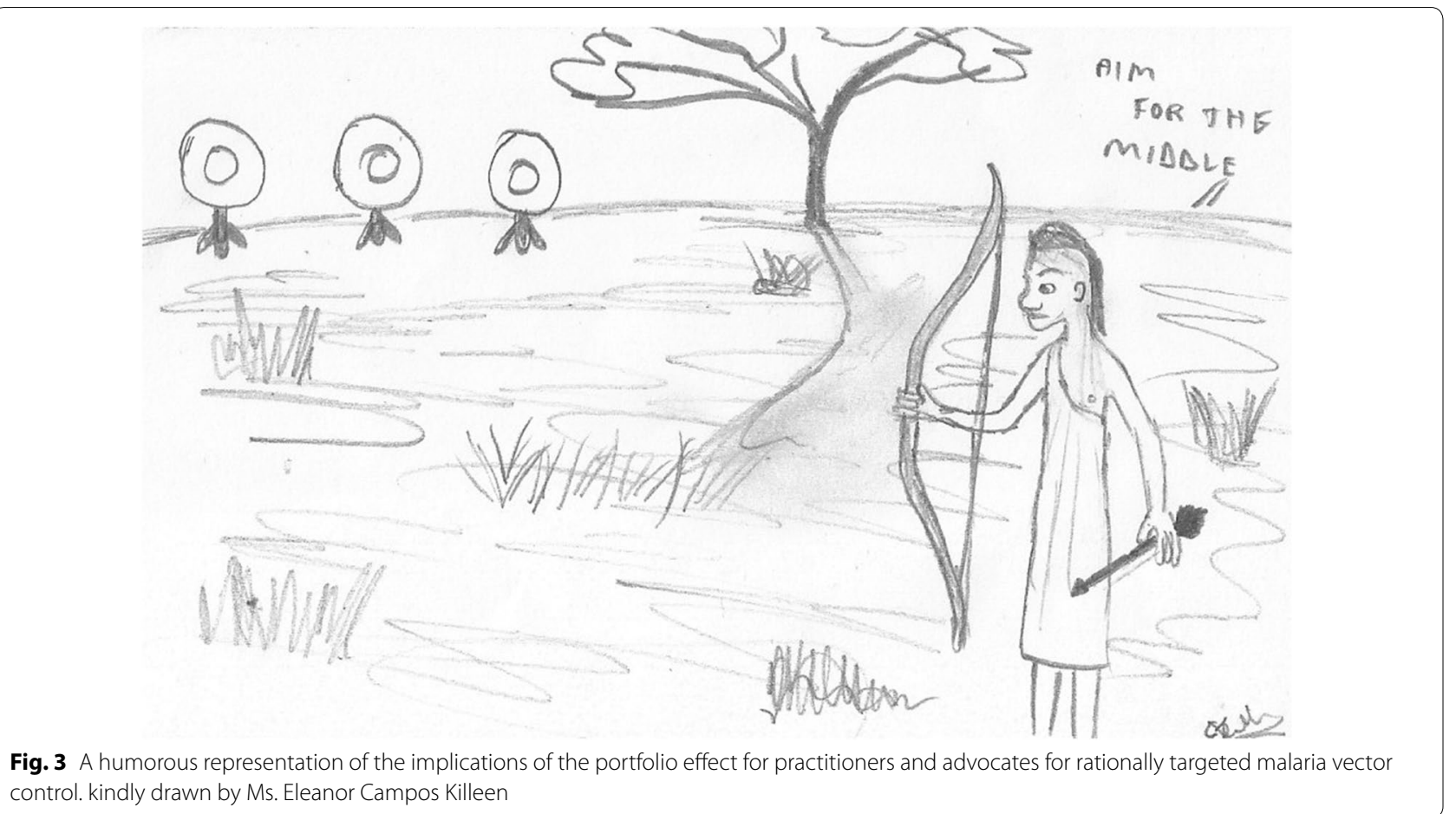

implement IRS, seasonal larviciding or even mass drug administration campaigns in real landscapes, and interannual variability introduces further scope for missing a moving target. We must settle for averaged and therefore imperfect timing optima for any seasonally implemented intervention. It is, therefore, important to take a realistic, pragmatic view of what impact may reasonably be expected from any given intervention approach, no matter how optimally seasonal delivery is timed based on averaged seasonality trends.

\section{Conclusions}

All these examples of the complexities that bolster malaria transmission against vector control interventions can be bamboozling and distract from very simple common principles that underlie them all. Malaria parasite populations that typically spread their reproductive bets across two or more vectors with different behaviours, ecological niches or seasonality dynamics will systematically be more difficult to eliminate than in the rare settings with a single vector species. Furthermore, where individual vector species spread their own reproductive bets across multiple aquatic habitat types, resting sites or blood sources, this creates refugia that limit the impact of any given vector control measure applied in any given time and place. And no matter how much detail we try to capture in mathematical models of vector biology and malaria transmission, they will always under-represent the full complexity and diversity of those interactions, so they are biased towards underestimating the resilience of malaria transmission against vector control. Whatever the shape of the expected response curve following introduction of a new vector control measure, the portfolio effect will tend to flatten it out to some extent. Given that the magnitude of such portfolio effects are unknown in any given location, the only sensible way to deal with their implications is to emphasize the need for cautious interpretation of entomological surveillance data, as well as simulation models extrapolating these trends into the future.

While several recent simulation models suggest good reasons for optimism going forward [30, 59, 60], harsh lessons $[39,61,62]$ learned from historical mistakes $[63$, 64] and awareness of ubiquitous but unquantifiable portfolio effects within malaria transmission systems both merit careful consideration. Looking ahead, it will be critically important to manage the expectations of stakeholders in malaria vector control and product development more conservatively and responsibly than has often been the case thus far $[39,61-65]$. While there are and always will be limitations to knowledge of malaria transmission and control, it is the maturity with which that knowledge is applied that will "determine whether we are living in an era of hubris or indeed in an age of eradication" [5] (Fig. 3). 


\section{Abbreviations}

LLINs: long lasting insecticidal nets; IRS: indoor residual spraying.

\section{Authors' contributions}

GFK drafted the manuscript in consultation with TR. Both authors read and approved the final manuscript.

\section{Author details}

${ }^{1}$ Environmental Health and Ecological Sciences Department, Ifakara Health Institute, Ifakara, United Republic of Tanzania. ${ }^{2}$ Vector Biology Department, Liverpool School of Tropical Medicine, Pembroke Place, Liverpool L3 5QA, UK. ${ }^{3}$ School of Biological, Earth and Environmental Sciences, University College Cork, Western Road, Cork, Republic of Ireland.

\section{Acknowledgements}

We kindly thank Ms. Eleanor Campos Killeen for drawing Fig. 3.

\section{Competing interests}

The authors declare that they have no competing interests.

\section{Availability of data and materials}

Data sharing is not applicable to this article as no datasets were generated or analysed during the current study.

\section{Consent for publication}

Not applicable.

\section{Ethics approval and consent to participate}

Not applicable.

\section{Funding}

None.

\section{Publisher's Note}

Springer Nature remains neutral with regard to jurisdictional claims in published maps and institutional affiliations.

Received: 22 March 2018 Accepted: 2 August 2018

Published online: 10 August 2018

\section{References}

1. Markowitz H. Portfolio selection. J Finance. 1952;7:77-91.

2. Schindler DE, Reed TE, Armstrong J. The portfolio concept in ecology and evolution. Front Ecol Evol. 2013;13:257-63.

3. McKenzie FE. Why model malaria? Parasitol Today. 2000;16:511-6.

4. McKenzie FE, Samba EM. The role of mathematical modeling in evidencebased malaria control. Am J Trop Med Hyg. 2004;71:94-6.

5. Smith TA, Chitnis N, Penny M, Tanner M. Malaria modeling in the era of eradication. Cold Spring Harb Perspect Med. 2017;7:a025460.

6. Woolhouse MEJ, Dye C, Etard JF, Smith T, Charlwood JD, Garnett GP, et al. Heterogeneities in the transmission of infectious agents: implications for the design of control programs. Proc Natl Acad Sci USA. 1997;94:338-42.

7. Smith DL, Dushoff J, Snow RW, Hay SI. The entomological inoculation rate and Plasmodium falciparum infection in African children. Nature. 2005:438:492-5

8. Smith DL, McKenzie FE, Snow RW, Hay SI. Revisiting the basic reproductive number for malaria and its implications for malaria control. PLoS Biol. 2007;5:e42.

9. Durnez L, Coosemans M. Residual transmission of malaria: an old issue for new approaches. In: Manguin S, editor. Anopheles mosquitoes-new insights into malaria vectors. Rijeka: Intech; 2013. p. 671-704.

10. Killeen GF. Characterizing, controlling and eliminating residual malaria transmission. Malar J. 2014;13:330

11. WHO. Guidance note-control of residual malaria parasite transmission Geneva: World Health Organization Global Malaria Programme; 2014. p. 5

12. WHO. Malaria terminology. WHO/HTM/GMP/2016. Geneva: World Health Organization; 2016. p. 31.
13. Molineaux L, Shidrawi GR, Clarke JL, Boulzaguet JR, Ashkar TS. Assessment of insecticidal impact on the malaria mosquito's vectorial capacity, from data on the man-biting rate and age-composition. Bull World Health Organ. 1979;57:265-74.

14. Molineaux L, Gramiccia G. The Garki project. Geneva: World Health Organ 1980.

15. Le Menach A, Takala S, McKenzie FE, Perisse A, Harris A, Flahault A, et al. An elaborated feeding cycle model for reductions in vectorial capacity of night-biting mosquitoes by insecticide-treated nets. Malar J. 2007:6:10.

16. Killeen GF, Smith TA. Exploring the contributions of bednets, cattle, insecticides and excito-repellency to malaria control: a deterministic model of mosquito host-seeking behaviour and mortality. Trans R Soc Trop Med Hyg. 2007;101:867-80.

17. Govella NJ, Okumu FO, Killeen GF. Insecticide-treated nets can reduce malaria transmission by mosquitoes which feed outdoors. Am J Trop Med Hyg. 2010:82:415-9.

18. Yakob L, Dunning R, Yan G. Indoor residual spray and insecticide-treated bednets for malaria control: theoretical synergisms and antagonisms. J R Soc Interface. 2011;8:799-806.

19. Killeen GF, Moore SJ. Target product profiles for protecting against outdoor malaria transmission. Malar J. 2012;11:17.

20. Kiware SS, Chitnis N, Devine GJ, Moore SJ, Majambere S, Killeen GF. Biologically meaningful coverage indicators for eliminating malaria transmission. Biol Lett. 2012;8:874-7.

21. Kiware SS, Chitnis N, Moore SJ, Devine GJ, Majambere S, Killeen GF. Simplified models of vector control impact upon malaria transmission by zoophagic mosquitoes. PLoS One. 2012;7:e37661.

22. Briët OJ, Chitnis N. Effects of changing mosquito host searching behav iour on the cost effectiveness of a mass distribution of long-lasting, insecticidal nets: a modelling study. Malar J. 2013;12:215.

23. Eckhoff PA. Mathematical models of within-host and transmission dynamics to determine effects of malaria interventions in a variety of transmission settings. Am J Trop Med Hyg. 2013;88:817-27.

24. Killeen GF, Chitnis N. Potential causes and consequences of behavioural resilience and resistance in malaria vector populations: a mathematical modelling analysis. Malar J. 2014;13:97.

25. Killeen GF, Seyoum A, Gimnig JE, Stevenson JC, Drakeley CJ, Chitnis N Made-to-measure malaria vector control strategies: rational design based on insecticide properties and coverage of blood resources for mosquitoes. Malar J. 2014:13:146.

26. Killeen GF, Govella NJ, Lwetoijera DW, Okumu FO. Most outdoor malaria transmission by behaviourally-resistant Anopheles arabiensis is mediated by mosquitoes that have previously been inside houses. Malar J. 2016;15:225.

27. Brady OJ, Godfray HC, Tatem AJ, Gething PW, Cohen JM, McKenzie FE, et al. Vectorial capacity and vector control: reconsidering sensitivty to parameters for malaria elimination. Trans R Soc Trop Med Hyg. 2016;110:107-17.

28. Killeen GF, Kiware SS, Okumu FO, Sinka ME, Moyes CL, Massey NC, et al. Going beyond personal protection against mosquito bites to eliminate malaria transmission: population suppression of malaria vectors that exploit both human and animal blood. BMJ Glob Health. 2017;2:e000198.

29. Killeen GF, Marshall JM, Kiware SS, South AB, Tusting LS, Chaki PP, et al. Measuring, manipulating and exploiting behaviours of adult mosquitoes to optimize malaria vector control impact. BMJ Global Health. 2017;2:e000212.

30. Kiware SS, Chitnis N, Tatarsky A, Wu S, Castellanos HMS, Gosling R, et al. Attacking the mosquito on multiple fronts: insights from the Vector Control Optimization Model (VCOM) for malaria elimination. PLoS One. 2017:12:e0187680.

31. Sinka ME, Bangs MJ, Manguin S, Rubio-Palis Y, Chareonviriyaphap T, Coetzee $M$, et al. A global map of dominant malaria vectors. Parasit Vectors. 2012;5:69.

32. Killeen GF, Chaki PP, Reed TE, Moyes CL, Govella NJ. Entomological surveillance as a cornerstone of malaria elimination: a critical appraisal. In: Dev V, Manguin S, editors. Towards malaria elimination - a leap forward. London: InTech; 2018. p. 403-29.

33. Sinka ME, Golding N, Massey NC, Wiebe A, Huang Z, Hay SI, et al. Modelling the relative abundance of the primary African vectors of malaria before and after the implementation of indoor, insecticide-based vector control. Malar J. 2016:15:142. 
34. Killeen GF, Seyoum A, Sikaala CH, Zomboko AS, Gimnig JE, Govella NJ, et al. Eliminating malaria vectors. Parasit Vectors. 2013;6:172.

35. Riveron JM, Ibrahim SS, Mulamba C, Djouaka R, Irving H, Wondji MJ, et al. Genome-wide transcription and functional analyses reveal heterogeneous molecular mechanisms driving pyrethroids resistance in the major malaria vector Anopheles funestus across Africa. G3 (Bethesda). 2017;7:1819-32.

36. Kaindoa EW, Matowo NS, Ngowo HS, Mkandawile G, Mmbando A, Finda $\mathrm{M}$, et al. Interventions that effectively target Anopheles funestus mosquitoes could significantly improve control of persistent malaria transmission in south-eastern Tanzania. PLoS One. 2017;12:e0177807.

37. Coluzzi M, Sabatini A, Petrarca V, Di Deco MA. Behavioural divergences between mosquitoes with different inversion karyotypes in polymorphic populations of the Anopheles gambiae complex. Nature. 1977;266:832-3.

38. Coluzzi M, Sabatini A, Petrarca V, Dideco MA. Chromosomal differentiation and adaptation to human environments in the Anopheles gambiae complex Trans Roy Soc Trop Med Hyg. 1979;73:483-97.

39. Killeen GF. A second chance to tackle African malaria vector mosquitoes that avoid houses and don't take drugs. Am J Trop Med Hyg. 2013:88:809-16.

40. Killeen GF, Kiware SS, Seyoum A, Gimnig JE, Corliss GF, Stevenson J, et al. Comparative assessment of diverse strategies for malaria vector population control based on measured rates at which mosquitoes utilize targeted resource subsets. Malar J. 2014;13:338.

41. White GB, Magayuka SA, Boreham PFL. Comparative studies on sibling species of the Anopheles gambiae complex (Dip., Culicidae): bionomics and vectorial activity of species A and species B at Segera, Tanzania. Bull Entomol Res. 1972;62:295-317.

42. Killeen GF, McKenzie FE, Foy BD, Bogh C, Beier JC. The availability of potential hosts as a determinant of feeding behaviours and malaria transmission by mosquito populations. Trans R Soc Trop Med Hyg. 2001;95:469-76.

43. Garrett-Jones C, Boreham P, Pant CP. Feeding habits of anophelines (Diptera: Culicidae) in 1971-1978, with reference to the human blood index: review. Bull Entomol Res. 1980;70:165-85.

44. Silver JB. Blood feeding and its epidemiological significance. Mosquito ecology: field sampling methods. Dordrecht: Springer; 2008. p. 677-769.

45. Gryseels C, Durnez L, Gerrets R, Uk S, Suon S, Set S, et al. Re-imagining malaria: heterogeneity of human and mosquito behaviour in relation to residual malaria transmission in Cambodia. Malar J. 2015;14:165.

46. Trung HD, Bortel WV, Sochantha T, Keokenchanh K, Briët OJ, Coosemans M. Behavioural heterogeneity of Anopheles species in ecologically different localities in southeast Asia: a challenge for vector control. Trop Med Int Health. 2005;10:251-62.

47. Van Bortel W, Trung HD, Hoi LX, Ham NV, Chut NV, Luu ND, et al. Malaria transmission and vector behaviour in a forested malaria focus in central Vietnam and the implications for vector control. Malar J. 2010;9:373.

48. WHO. Global plan for insecticide resistance management in malaria vectors (GPIRM). Geneva: World Health Organization; 2012. p. 130.

49. Muirhead-Thomson RC. Mosquito behaviour in relation to malaria transmission and control in the tropics. London: Edward Arnold \& Co.; 1951.

50. Holstein MH. Biology of Anopheles gambiae. Geneva: World Health Organization; 1954

51. Gillies MT, De Meillon B. The Anophelinae of Africa South of the Sahara (Ethiopian zoogeographical region). Johannesburg: South African Institute for Medical Research; 1968

52. Simard F, Ayala D, Kamdem GC, Pombi M, Etouna J, Ose K, et al. Ecological niche partitioning between Anopheles gambiae molecular forms in Cameroon: the ecological side of speciation. BMC Ecol. 2009;9:17.

53. Gimonneau G, Pombi M, Choisy M, Morand S, Dabire RK, Simard F. Larval habitat segregation between the molecular forms of the mosquito Anopheles gambiae in a rice field area of Burkina Faso, West Africa. Med Vet Entomol. 2012;26:9-17.

54. Diabate A, Dabire RK, Kim EH, Dalton R, Millogo N, Baldet T, et al. Larval development of the molecular forms of Anopheles gambiae (Diptera:
Culicidae) in different habitats: a transplantation experiment. J Med Entomol. 2005;42:548-53.

55. Killeen GF, Mukabana WR, Kalongolela MS, Kannady K, Lindsay SW, Tanner $M$, et al. Habitat targetting for controlling aquatic stages of malaria vectors in Africa. Am J Trop Med Hyg. 2006;74:517-8.

56. Fillinger $U$, Lindsay SW. Larval source management for malaria control in Africa: myths and reality. Malar J. 2011;10:353.

57. Briercliffe R, Dalryimple-Champney W. Discussion on the malaria epidemic in Ceylon 1934-1935. Proc R Soc Med. 1935;29:537-62.

58. Dao A, Yaro AS, Diallo M, Timbine S, Huestis DL, Kassogue Y, et al. Signatures of aestivation and migration in Sahelian malaria mosquito populations. Nature. 2014;516:387-90.

59. Smith DL, Cohen JM, Chiyaka C, Johnston G, Gething PW, Gosling R, et al. A sticky situation: the unexpected stability of malaria elimination. Philos Trans R Soc Lond B Biol Sci. 2013;368:20120145.

60. Slater HC, Ross A, Ouedraogo AL, White LJ, Nguon C, Walker PG, et al. Assessing the impact of next-generation rapid diagnostic tests on Plasmodium falciparum malaria elimination strategies. Nature. 2015;528:S94-101.

61. Najera JA. Malaria control: achievements, problems and strategies. Parassitologia. 2001;43:1-89.

62. Najera JA, Gonzalez-Silva M, Alonso PL. Some lessons for the future from the Global Malaria Eradication Programme (1955-1969). PLoS Med. 2011;8:e1000412

63. MacDonald G. The epidemiology and control of malaria. London: Oxford University Press; 1957

64. Garrett-Jones C. Prognosis for interruption of malaria transmission through assessment of the mosquito's vectorial capacity. Nature. 1964:204:1173-5.

65. Roberts $L$, Enserink M. Did they really say... eradication? Science. 2007:318:1544-5.

66. Moiroux N, Gomez MB, Pennetier C, Elanga E, Djènontin A, Chandre $F$, et al. Changes in Anopheles funestus biting behaviour following universal coverage of long-lasting insecticidal nets in Benin. J Infect Dis. 2012;206:1622-9.

67. Moiroux N, Damien GB, Egrot M, Djenontin A, Chandre F, Corbel V, et al. Human exposure to early morning Anopheles funestus biting behavior and personal protection provided by long-lasting insecticidal nets. PLoS One. 2014;9:e104967

68. Sougoufara S, Diedhiou SM, Doucoure S, Diagne N, Sembene PM, Harry $M$, et al. Biting by Anopheles funestus in broad daylight after use of longlasting insecticidal nets: a new challenge to malaria elimination. Malar J. 2014;13:125.

69. Sougoufara S, Thiaw O, Cailleau A, Diagne N, Harry M, Bouganali C, et al. The impact of periodic distribution campaigns of long-lasting insecticide-treated bed nets on malaria vector dynamics and human exposure in Dielmo, Senegal. Am J Trop Med Hyg. 2018;98:1343-52.

70. Russell TL, Govella NJ, Azizi S, Drakeley CJ, Kachur SP, Killeen GF. Increased proportions of outdoor feeding among residual malaria vector populations following increased use of insecticide-treated nets in rural Tanzania. Malar J. 2011:10:80.

71. Meyers Jl, Pathikonda S, Popkin-Hall ZR, Medeiros MC, Fuseini G, Matias A, et al. Increasing outdoor host-seeking in Anopheles gambiae over 6 years of vector control on Bioko Island. Malar J. 2016;15:239.

72. Yohannes M, Boelee E. Early biting rhythm in the afro-tropical vector of malaria, Anopheles arabiensis, and challenges for its control in Ethiopia. Med Vet Entomol. 2012;26:103-5.

73. Gillies MT, Coetzee M. A supplement to the Anophelinae of Africa South of the Sahara (Afrotropical region). Johannesburg: South Afr Med Res Institute; 1987.

74. Kawada H, Dida GO, Sonye G, Njenga SM, Mwandawiro C, Minakawa $\mathrm{N}$. Reconsideration of Anopheles rivulorum as a vector of Plasmodium falciparum in western Kenya: some evidence from biting time, blood preference, sporozoite positive rate, and pyrethroid resistance. Parasit Vectors. 2012;5:230 